\title{
Estimation of kinetic parameters associated with the digestibility of tropical forages using a new in vitro gas production procedure
}

\author{
M. K. Theodorou' ${ }^{1}$, B. A. Williams ${ }^{1}$, A. Brooks ${ }^{1}$, M. S. Dhanoa' ${ }^{1}$, A. B. McAllan ${ }^{1}$ and M. Gill ${ }^{2}$ \\ ${ }^{1}$ AFRC Institute of Grassland and Environmental Research, Plas Gogerddan, Abeyrstwyth, Dyfed SY23 3EB \\ ${ }^{2}$ Natural Resources Institute, Chatham Maritime, Kent ME4 4TB
}

\section{Introduction}

A simple yet sensitive technique was developed to provide precise information on the digestion kinetics of tropical crops intended for use as ruminant foods.

\section{Material and methods}

Dried and ground forages were mixed with an anaerobic medium, inoculated with rumen contents and incubated in gas-tight culture bottles at $39^{\circ} \mathrm{C}$. A pressure transducer with light-emitting diode digital read-out meter was used during time-course studies to monitor the accumulation of fermentation gases in the head-space of culture bottles. Following measurement of gas pressure and gas volume, collected gas was discarded, the transducer assembly withdrawn from the bottle closure and the bottle returned to the incubator until the next measurement.

Gas pressures from five replicate culture bottles were plotted against corresponding gas volumes and the

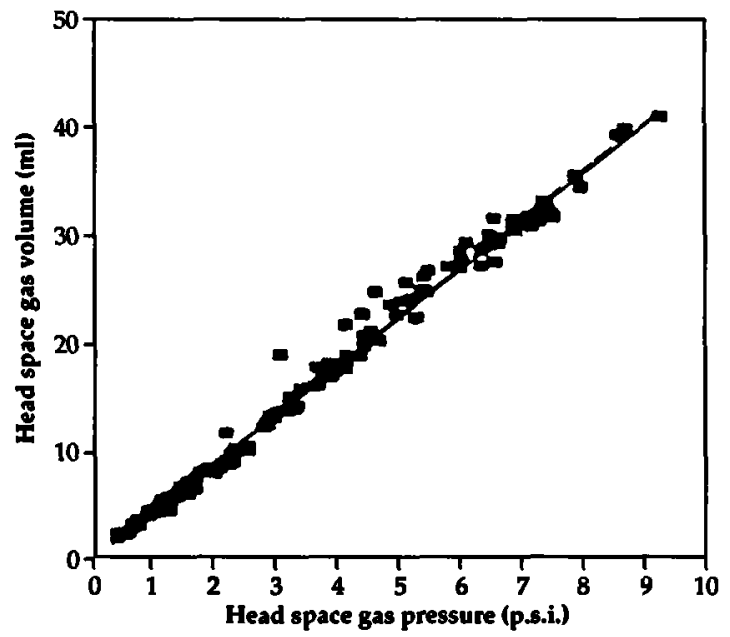

Figure 1 Regression analysis: $y=4.539 x-0.554\left(R^{2}=0.992\right)$. data subjected to analysis by linear regression (Figure 1). Cumulative gas was then determined by summation of predicted (regression corrected) gas volumes. A single pool exponential equation and nonlinear regression was used to describe the experimental gas production profiles.

\section{Results}

An example of the output from this procedure is shown in Figure 2. These profiles were obtained from the fermentation of $1 \mathrm{~g}$ (dry matter) of pea forage which was grown in Syria and harvested at monthly intervals from April to June 1988. Values for rate of gas production (per $\mathrm{h}$ ) and gas pool size $(\mathrm{ml})$ obtained from each of these profiles are shown in Table 1. These results clearly demonstrate a relationship between time of harvest and decrease in nutritive value of pea forage. As time of harvest increased, both rate of gas production and gas pool size decreased (Table 1).

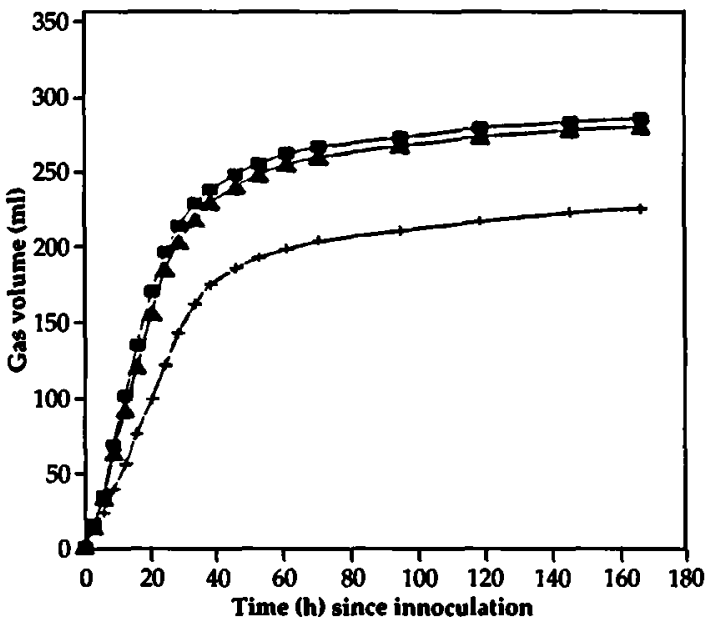

Figure 2 Gas accumulation profiles: $=$ April, 1998; $\Delta=$ May 1988; + = June, 1988. 
Table 1 Kinetics of gas production for pea forage

\begin{tabular}{lccc}
\hline Substratet & Harvest date & $\begin{array}{c}\text { Rate of gas } \\
\text { production (per h) }\end{array}$ & $\begin{array}{c}\text { Gas pool size } \\
\text { (ml) }\end{array}$ \\
\hline Pea forageł & April 1988 & 0.058 & 287.5 \\
& May 1988 & 0.053 & 279.3 \\
& June 1988 & 0.043 & 227.1 \\
\hline
\end{tabular}

+ E. Carter of ICARDA, Syria, is kindly acknowledged for provision of ground and dried substrates.

$\ddagger$ Each bottle contained $1 \mathrm{~g}$ dry matter of ground substrate.

\section{Discussion}

Determinations of gas production profiles by use of a pressure transducer is a straight forward and inexpensive procedure. The technique provides precise information which can be used to rank tropical forages with respect to their fermentability (nutritive value) in vitro. Further research is now under way to compare values obtained from gas production assays with those from other in vitro and in vivo digestibility procedures, including polyester bag analysis. 